\title{
Why Using Organic Fertilizers and Biopesticides is Important for Food Legumes Production in Jordan?
}

\author{
${ }^{1}$ Mohunnad Massimi, ${ }^{2}$ Muhammad Haseeb, ${ }^{3}$ Nour Abdel Rahman \\ ${ }^{1}$ Norman Borlaug Fellow of USDA; FAS. Ministry of Agriculture, Zarqa Extension Department, P.O.Box: 1433. Zarqa. 13110. Jordan \\ ${ }^{2}$ Florida A\&M, University, Center for Biological Control, College of Agriculture \& Food Sciences. Tallahassee. 32307. U.S.A \\ 3Jordanian Geologists Association, Geology \& Environment, P.O.Box: 1433. Zarqa.13110. Jordan
}

Correspondence Author: Mohunnad Massimi,Norman Borlaug Fellow of USDA; FAS. Ministry of Agriculture, Zarqa Extension Department, P.0.Box: 1433. Zarqa.13110. Jordan

E-mail: mohunnad.massimi@moa.gov.jo

Received date: 12 November 2018, Accepted date: 10 January 2019, Online date: 25 January 2019

Copyright: (c) 2019MohunnadMassimiet al., This is an open-access article distributed under the terms of the Creative Commons Attribution License, which permits unrestricted use, distribution, and reproduction in any medium, provided the original author and source are credited.

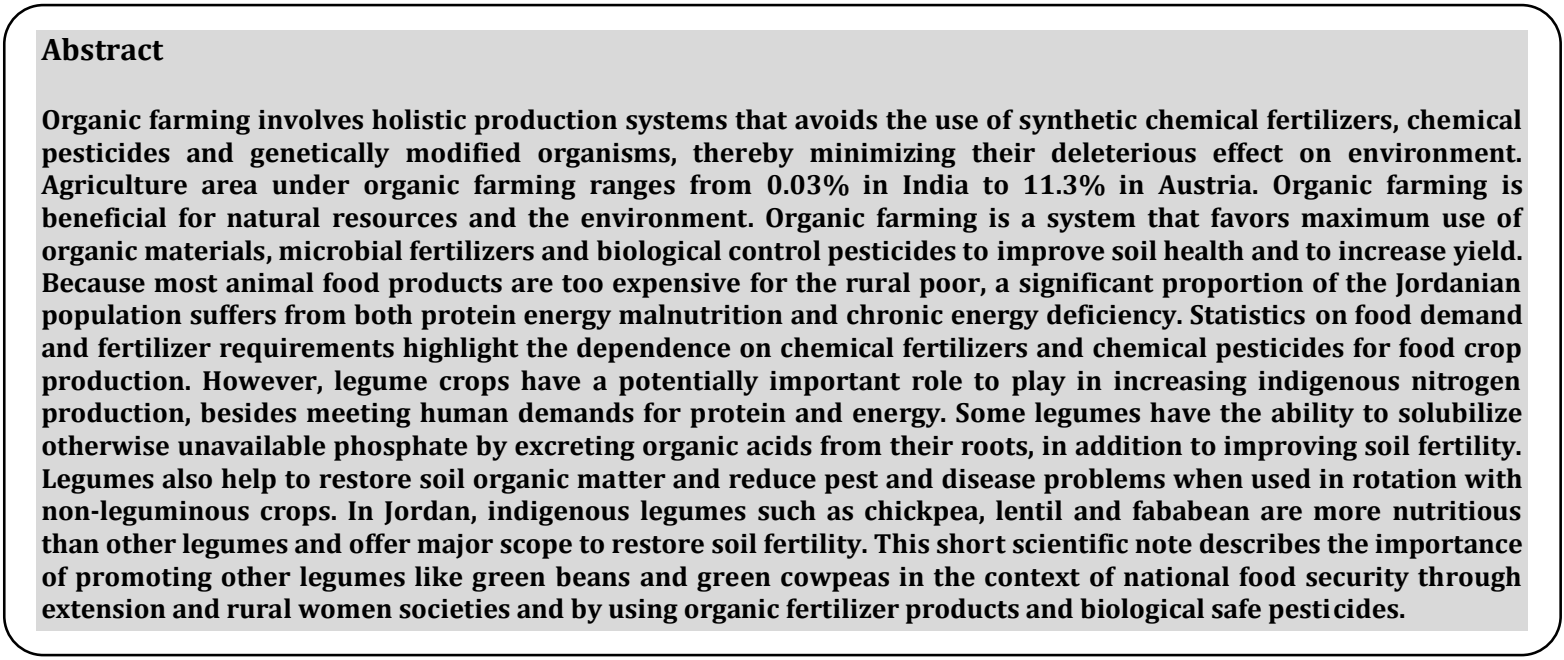

Key words: biopesticides; entomology; environment; export; health; organic,

\section{INTRODUCTION}

Food legumes are major food components on the dinner of Jordanian families. The major traditional food legumes are chickpea and lentil. It was estimated that the total planted area of chickpea in Jordan during (1997) was 1996.9 hectares. However, lentil was 3081 hectares. Currently, due to the economic loss resulting from increasing labor costs, most of the local market of chickpeas and lentils are imported from abroad. According to the statistics of the Department of Statistics (DOS) in 2016, the area of chickpeas planted in Jordan is about 685 hectares and a lentil is about 104 hectares [2].

Legume crops require relatively fewer water requirements than livestock production. Food legumes are a protein-rich health food, an alternative to red meat and a strategic solution to address the risk of depletion of water resources in Jordan. According to the report of the Arab Forum for Environment and Development (AFED) in 2015, if the Arab citizen reduced the consumption of red meat by $25 \%$ (or $17 \mathrm{~kg}$ per person per year), then 27 billion $\mathrm{m}^{3}$ of water will be saved considering that the production of $1 \mathrm{~kg}$ of meat needs $16 \mathrm{~m}^{3}$ of water [1].

The dissemination of the concepts of organic agriculture and biological control is imperative in the culture of rural Jordanian women, especially in relation to food products produced in accordance with the Food and Agricultural Organization (FAO's) approach to food legumes. 
The purposes of this project include:

- Diversification in the cultivation of food legumes and non-traditional crops such as green beans and green cowpeas instead of chickpeas, and lentils.

- To spread the culture of cultivating the appropriate improved varieties of these crops and to put them in the list of consumers on the Jordanian dinner to contain the same quantity of protein and the similar quality of animal protein.

- Encourage the adoption and cultivation of these varieties and include them in the schedules of the crop rotation as an organic fertilizer, due to its ability to stabilize the atmospheric nitrogen through the bacteria of roots called Rhizobium.

- Introduce the concepts of organic agriculture using organic fertilizers manufactured and biological pesticides in the culture of reducing the damage of chemical pesticides and fertilizers and their residues in agricultural food products.

- Increase the financial return (Jordan Dinar per hectare) where the product has a high marketing price and a high exporting opportunity.

The aims of this scientific note is to describe and compare the advantages of using organic fertilizers and biopesticides to produce green beans and green cowpeas as opposed to the use of chemical pesticides in Jordan. With a focus recommendation on the proper procedures for safe environmental agriculture, safe healthy food, high marketing price, and export advantage.

\section{MATERIALS AND METHODS}

The improved varieties of green beans and green cowpeas are planted in Jordan on both edges of a ridge, ridges spaced a part of $75-\mathrm{cm}$, with three seeds injected at a depth of $2-\mathrm{cm}$. The sowing process is repeated on the same edge of a bridge at a distance of $15-\mathrm{cm}$, where they are injected in the upper third of a ridge. Surface irrigation is used at a rate of $40-55 \mathrm{~m}^{3}$ once every 6 to 11 days. The demonstration was conducted at Rusayfah region, Jordan. It was planted on April 18 2018, keeping 1 variety of green bean (Valentino) and 1 variety of green cowpea (California Black Eye) replicated two times. Each replicate represented by 9 rows of organic treatments and 9 rows of chemical treatments.

An organic liquid fertilizer product containing 12\% Humic acid and 3\% Fulvic acid is recommended to be added with irrigation water after planting two weeks and repeated the addition every two weeks through the growing season. Farmers are advised to use this organic fertilizer at a rate of $500 \mathrm{~cm}^{3}$ per 0.1 hectare in each addition process. Iowa State University Extension and Outreach in 2013 reported many positive effects of substances such as Humic and Fulvic acids on plant growth [3]. At low concentrations, Humic acid increased the vegetative growth of soybean and corn. Thus, stimulation of root growth may improve plant resistance to disease, and plant response to feeding by herbivores and nematodes, and water stress caused by drought.

Due to its high Calcium and alkaline soil needs, a manufactured liquid organic fertilizer is added to those crops which containing $10 \%$ Calcium Oxide and $30 \%$ Carboxylic Acid. The rate of addition with irrigation water is 1-2 litres per 0.1 hectare at the time of the emergence of three true leaves, where Oxygen helps to aerate the soil and remove salts and Sodium on the soil granules and thus treat alkaline salinity and minimizing the toxic effects of salts. Further, positive benefits include improved roots growth, improved vegetative growth, and increased nutrients uptake, because the salts increase the toxic osmotic stress of the soil and thus cause drought and imbalance of the nutrients.

One of the most important organic products manufactured in Jordan is a liquid compound containing the active ingredient organically coated Copper-Phosphate. It has $10 \%$ Copper and $10 \%$ Phosphorus. The comparative advantage of this product is that its use as a fertilizer for plant nutrition where Phosphorus is needed by pulses such as Calcium. Also, it can be added with a foliar spray at a rate of 100-125 mm per 200 litres of water or with irrigation water at a rate of 500-1000 mm per 0.1 hectare.

The active ingredient is an organically coated Copper-Phosphate that is persistent on plant leaves and in the soil and it has a systematic impact that stimulates the production of phytoalexines and strengthens plant cell walls and plant tissues, which works to stimulate plant growth and to prevent plant dwarfing. Thus, preventing the penetration of fungus hyphae and bacteria, surrounding the infected spots with halo, and protecting the aerial and ground parts of the plant. It used to protect plants against diseases such as; Anthracnose, molds, rots, mildews, and blights. Further, it can be used to combat against fungal wilts (Fusarium and Verticillium), and fungal damping off (Fusarium and Pythium).

In contrast, vegetable growers in Jordan use a chemical systematic fungicide to control powdery mildews and molds. This fungicide has a residual effect and its active ingredient is Hexaconazole 5\%. The dosage ranges between 7-8 mm per 20 liters of water up to 8-20 mm for 20 litres of water, and the safety period is 3 days up to 21 days.

For biopesticides and organic foliar spray fertilizers, it is necessary to use a distributing adhesive material. This biological material acts to moisturize surfaces and improve its absorption of the spraying solutions through leaves. A Jordan market has an emulsified concentrate (EC) organic matter that is manufactured for this purpose. The active ingredient is Nitrogen Polymer, $2.5 \%$ Nitrogen, and $35 \%$ organic matter. Nitrogen is slow to release, thus gaining spraying solutions a long- lasting effect. This material facilitates the penetration of spray solutions in the leaves because of the high compatibility and synergist ability with the most solutions that sprayed on the vegetative growth and thus increasing the efficiency of biopesticides and organic foliar spray fertilizers. Other benefits are that it increases the consistency for the size of spray solution droplets and prevents its volatilization on neighboring fields through drift reduction, as well as it reduces solutions odors by reducing evaporation. The recommended dosage with foliar spray fertilizers, insects, and fungal biopesticides is 100-150 mm per 200 liters of water. However, the recommended dosage with herbs biopesticides is $250-500 \mathrm{~mm}$ per 100 liters of water. Using this adhesive material reduces work and initial input costs.

On the other hand, biopesticides are very important for pest control. Pests may be herbs, insects or fungal and bacterial diseases. The use of biopesticides is a key element in organic agriculture and integrated pest management strategies. 
Because chemical pesticides have a direct negative impact on soil, air, water, plant and animal tissues, and the human body, biopesticides derived from plants natural extracts or compounds from microorganisms which could be an appropriate alternative to chemical pesticides to produce healthy food with safe environmental practices.

The biopesticide extract of Neem oil substance and its active ingredient is called Azadirachtin $0.18 \%$ used in the control of insects such as roots and leaves cutworms, aphids, and spiders, and it is used to control fungal diseases also. Usage rate is $20 \mathrm{~mm}$ per 20 liters of water and safety period only 1 day.

In contrast, Jordan farmers use a chemical compound of its active ingredient called Malathion 50\%. It can be used to control leaves cutworms and aphids. Usage rate is $30 \mathrm{~mm}$ per 20 liters of water and safety period is 7 days. In the case of soil worms and roots cutworms, farmers use a chemical pesticide with irrigation water. The active ingredient is Dimethoate $40 \%$ used at a rate of $250 \mathrm{~mm}$ per 200 liters of water. The common use is spraying at $30 \mathrm{~mm}$ per 20 liters of water and safety period is 14 days. Dimethoate $40 \%$ is recommended to combat aphids, leaf miners, leaves and roots cutworms. These two chemical insecticides belong to the group of Organo-Phosphorus pesticides. They are chlorinated carbon compounds and persistent organic pollutants (POP's) that are highly toxic and decompose slowly in the environment and they are transported to very long distances.

The anti spider biopesticide has an active ingredient and substance called Matrine $0.3 \%$ (a natural plant alkaloid, derived from wild medical plants which is active against several pest arthropods). The biopesticide package contains 3 gm of active ingredient and $997 \mathrm{gm}$ inert substance. It can be used also to control cutworms, aphids and leaf miners. Recommended dosage rate is $100-150 \mathrm{~mm}$ per 100 liters of water and safety period is 5 days. The chemical pesticide commonly used in Jordan to control spiders and mites called Abamectin 1.8\%. The same pesticide is recommended to be used to control leaf miners. It is used at a rate of $20 \mathrm{~mm}$ per 20 liters of water and safety period is 7-10 days.

Both biopesticides of Azadirachtin 0.18\% and Matrine $0.3 \%$ are registered with the Institute of market ecology (IMO) as an international agency for inspection, certification and quality assurance of eco-friendly products. For more than 20 years, (IMO) has been active in the field of organic certification. Farmers are advised to accurately document their cultural practices using those products to get an access to organic farming certificates.

Table 1 explains all biopesticides, chemical insecticides and chemical fungicides used in this demonstration as classified according to its toxicity to humans, animals, bees and fish based on the lethal dose $50 \%$.

Table 1: A brief comparison of all biopesticides and all chemical pesticides toxicity for humans, animals, bees and fish based on the lethal dose (LD50).

\begin{tabular}{|c|c|c|}
\hline \multirow{2}{*}{ Active Ingredient \& Percentage } & \multicolumn{2}{|c|}{ Toxicity $^{\text {a }}$} \\
\cline { 2 - 3 } & Humans \& Animals & Bees \& Fish \\
\hline Azadirachtin 0.18\% & - & 0 \\
\hline Matrine 0.3\% & - & + \\
\hline Malathion 50\% & $+/-$ & + \\
\hline Dimethoate 40\% & + - & + \\
\hline Abamectin 1.8\% & - & + \\
\hline
\end{tabular}

${ }^{\mathrm{a}}+$ : High or extreme high toxicity, +/-: Medium toxicity, -: low toxicity, and 0: Non-toxic.
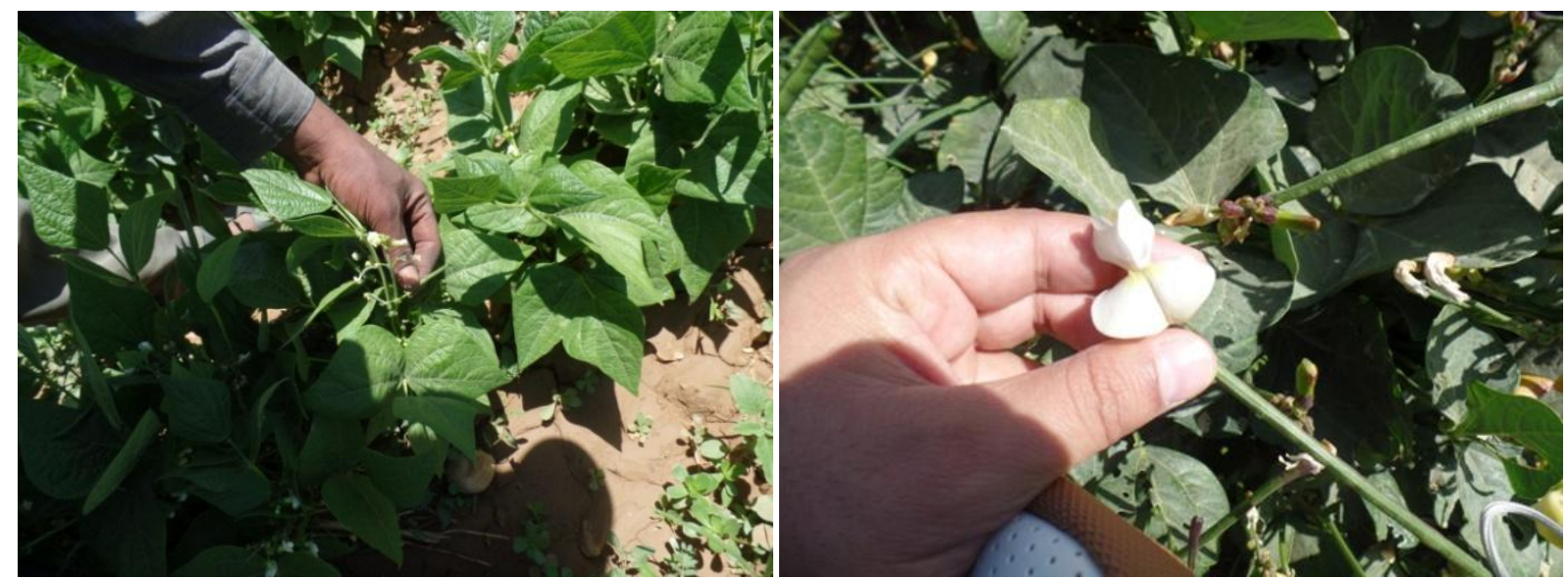

Figure.1and 2. Phosphorus fertilization stimulates flowering and pods formation in both green beans (Phaseolus vulgaris) and green cowpeas (Vigna unguiculata) respectively. 


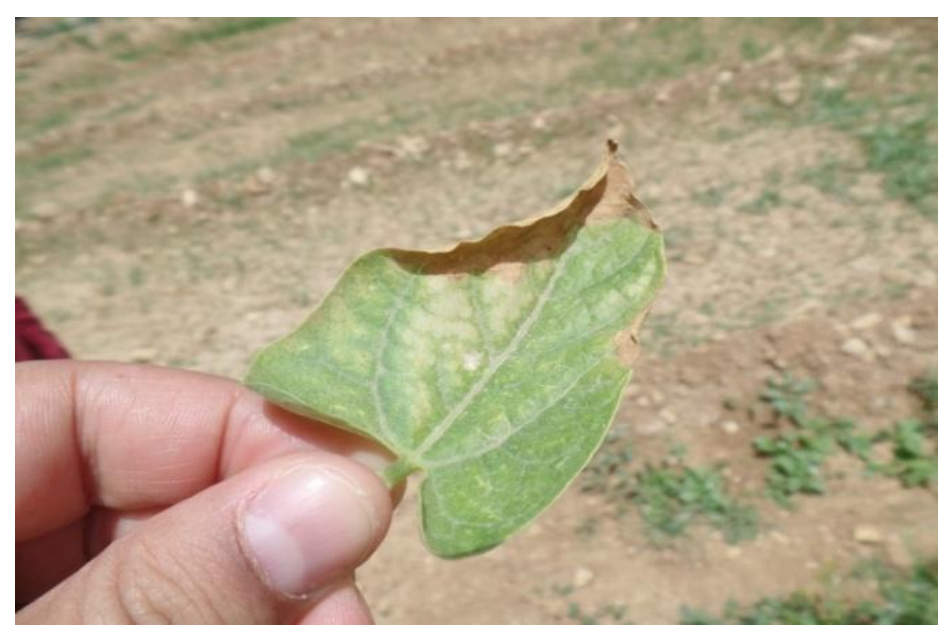

Figure. 3. Spiders impact on green cowpea (Vigna unguiculata) variety leaves in Rusayfah demonstration site

\section{CONCLUSION}

In summary, the use of organic fertilizers and biopesticides in food legumes production in Jordan is a critical strategy in the integrated pest management, safe environmental practices, and exportable and healthy food production.

\section{ACKNOWLEDGEMENT}

Special thanks extended to Dr.Lambert Kanga (CAFS, FAMU), Dr. Jesusa Legaspi (USDA, ARS), Dr. Nizar Haddad (NARC, Jordan) and Eng. Abd Al-Hadi Al-Falahat (AEA, Jordan) for their counseling and help.

\section{Funding Information}

Funding support for this study was provided by the National Center for Agricultural Research (NARC, Jordan).

\section{CONFLICT OF INTEREST}

Authors declare no conflict of interest.

\section{REFERENCES}

1. Arab Forum for Environment and Development, 2015. Annual Report 8. Sustainable Consumption. AFED.

2. Department of Statistics, 2016. Survey. Agriculture. DOS website, Government of Jordan.

3. Wright, D., and A. Lenssen, 2013. Humic and Fulvic Acids and Their Potential in Crop Production. Department of Agronomy, Iowa State University.

\section{Author Biography sample}

Mohunnad Massimi a Ph.D. candidate and a Norman Borlaug Fellow of USDA; FAS (Irrigation Modeling Fellow) certified by the Florida A\&M University. works at the research of crops production techniques and rural development strategies, Jordan's Ministry of Agriculture.

Muhammad Haseeb is an Assistant Professor in the Center for Biological Control, Florida A\&M University. He received his BS (1989) and MS (1991) degrees in Entomology from Gomal University, Pakistan and a Ph.D. degree (2001) in Entomology from Chiba University, Japan. He was a Postdoctoral Research Fellow at the Texas A\&M University in 2001. The focus of his research is to develop pest management strategies for the effective management of invasive and established pest insects in specialty crops (fruits, vegetables, and nuts). The overall objectives of his extension and outreach are to impart training to stakeholders and clientele with respect to crop productivity and profitability. The major objective of his teaching assignment is to develop and offer graduate and undergraduate courses.

Nour Abdel Rahman, a member of Jordanian Geologists Association, specialized in geology \& environment engineering and certified by the Hashemite University. 